\title{
Synthesis and Characterization of Palladium(II) Complexes of meso-Substituted
}

\section{[14]Tribenzotriphyrin(2.1.1)}

Zhaoli Xue $^{\dagger *}$, Yemei Wang ${ }^{\dagger}$ and John Mack ${ }^{* *}$, Yuanyuan Fang ${ }^{\S}$, Zhongping $\mathrm{Ou}^{\dagger}$ Weihua Zhu ${ }^{\dagger}$ and Karl M. Kadish ${ }^{{ }^{*}}$

${ }^{\dagger}$ School of Chemistry and Chemical Engineering, Jiangsu University, Zhenjiang 212013, China

${ }^{\ddagger}$ Department of Chemistry, Rhodes University Grahamstown 6140, South Africa

${ }^{\S}$ Department of Chemistry, University of Houston, Houston, Texas 77204-5003, United States

E-mail: zhaolixue@ujs.edu.cn (Z.X.), j.mack@ru.ac.za (J.M.), kkadish@uh.edu (K.M.K). 


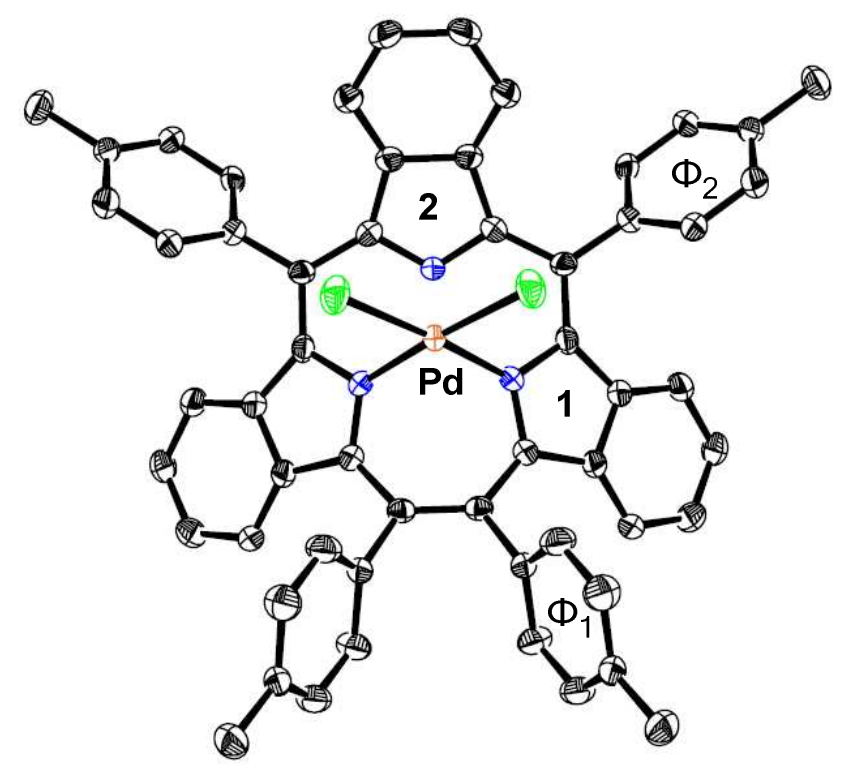

Table S1. Dihedral angles between meso-phenyl rings and the triphyrin mean plane (deg) ${ }^{\mathrm{a}}$.

\begin{tabular}{|c|c|}
\hline & 2 (deg) \\
\hline $\boldsymbol{\Phi}_{1}{ }^{\mathbf{a}}$ & 66.5 \\
\hline $\boldsymbol{\Phi}_{\mathbf{2}}$ & 32.7 \\
\hline Pyrrole 1 $^{\mathbf{b}}$ & 147.9 \\
\hline Pyrrole 2 $^{\mathbf{b}}$ & 140.5 \\
\hline
\end{tabular}

${ }^{a}$ Angles $\Phi_{\mathrm{i}}(\mathrm{i}=1,2)$ are defined by the dihedral angles between meso-phenyl rings and the triphyrin mean plane ${ }^{b}$ Pyrrole 1 and 2 means the pyrroles including N(1) and N(2), respectively. Angles is defined by the dihedral angles between meso-phenyl rings and the triphyrin mean plane 


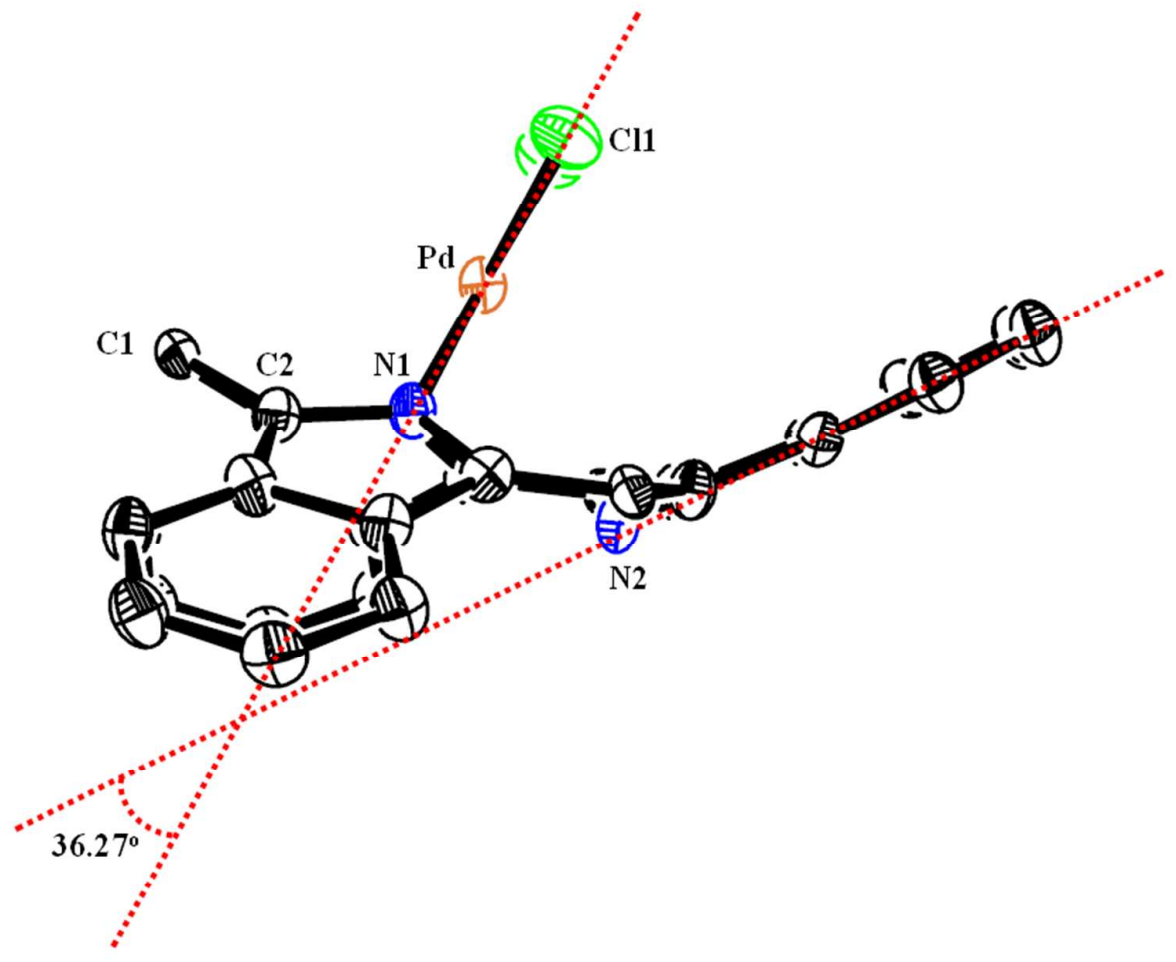

Figure S1. ORTEP diagrams of 2. Side views. Thermal ellipsoids are drawn in $50 \%$ probability with phenyl groups omitted. Solvent molecules and hydrogen atoms are also omitted for clarity. 


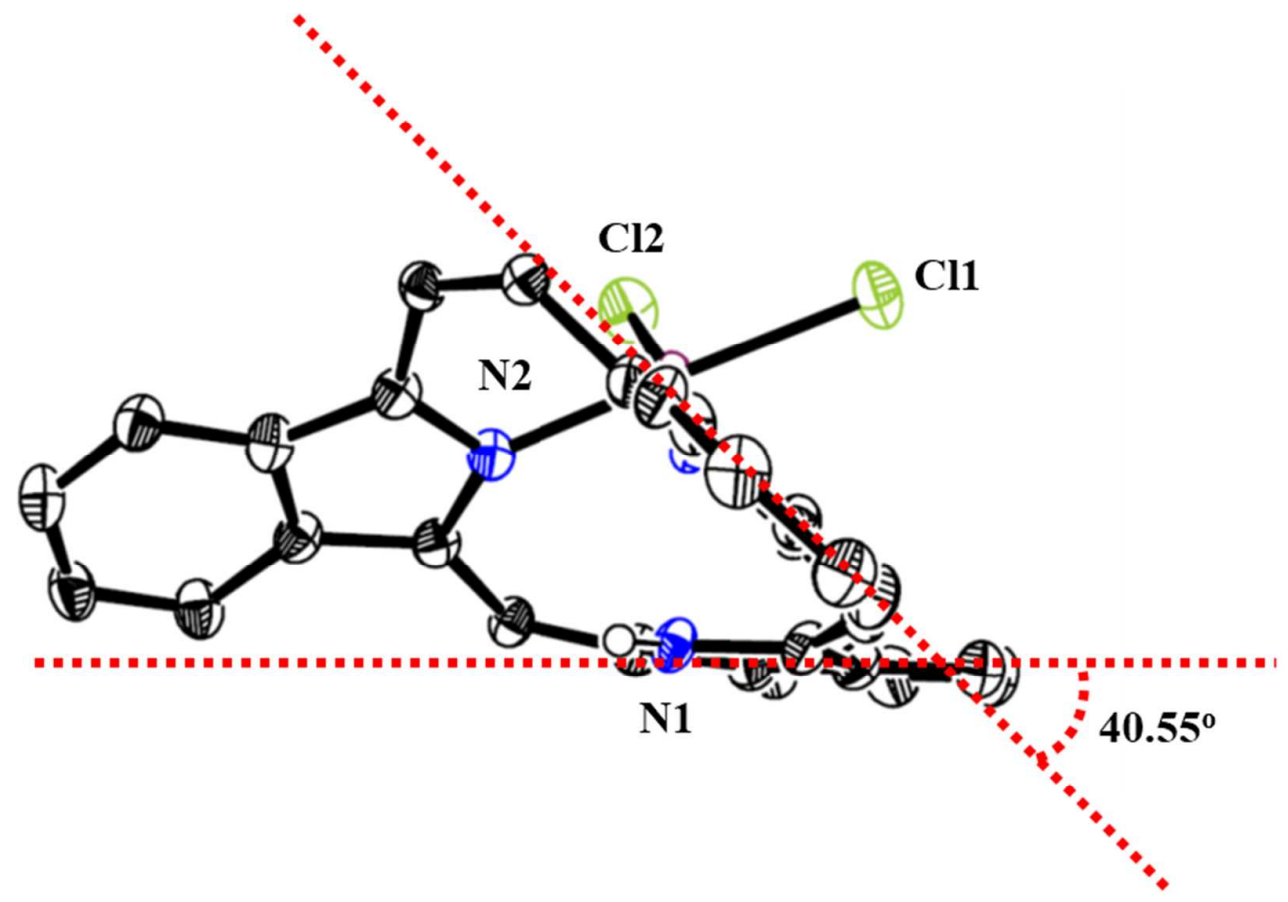

Figure S2. ORTEP diagrams of 2. Side views. Thermal ellipsoids are drawn in 50\% probability with phenyl groups omitted. Solvent molecules and hydrogen atoms are also omitted for clarity. 


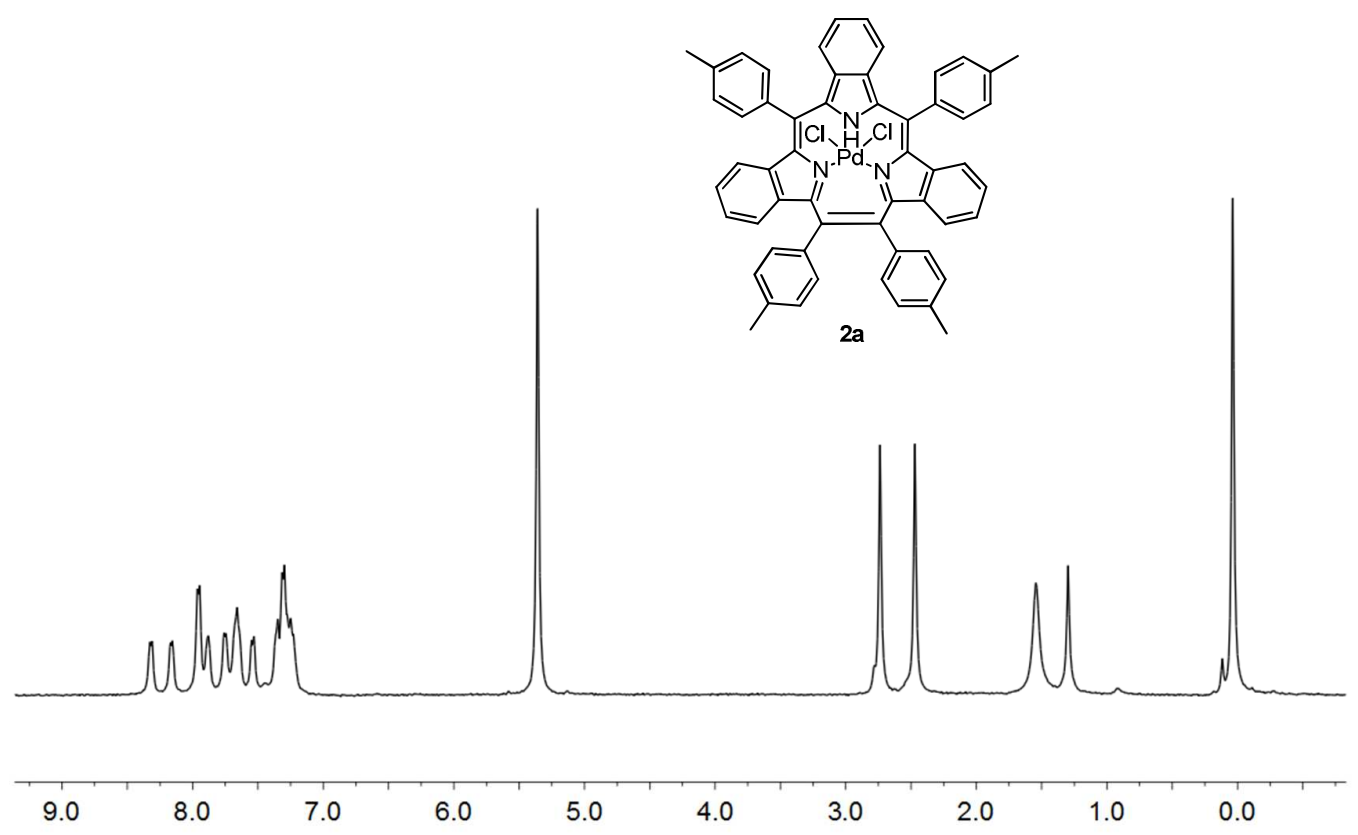

Figure S3. ${ }^{1} \mathrm{H}$ NMR spectra of $\mathbf{2 a}$ in $\mathrm{CD}_{2} \mathrm{Cl}_{2}$ at $298 \mathrm{~K}$.

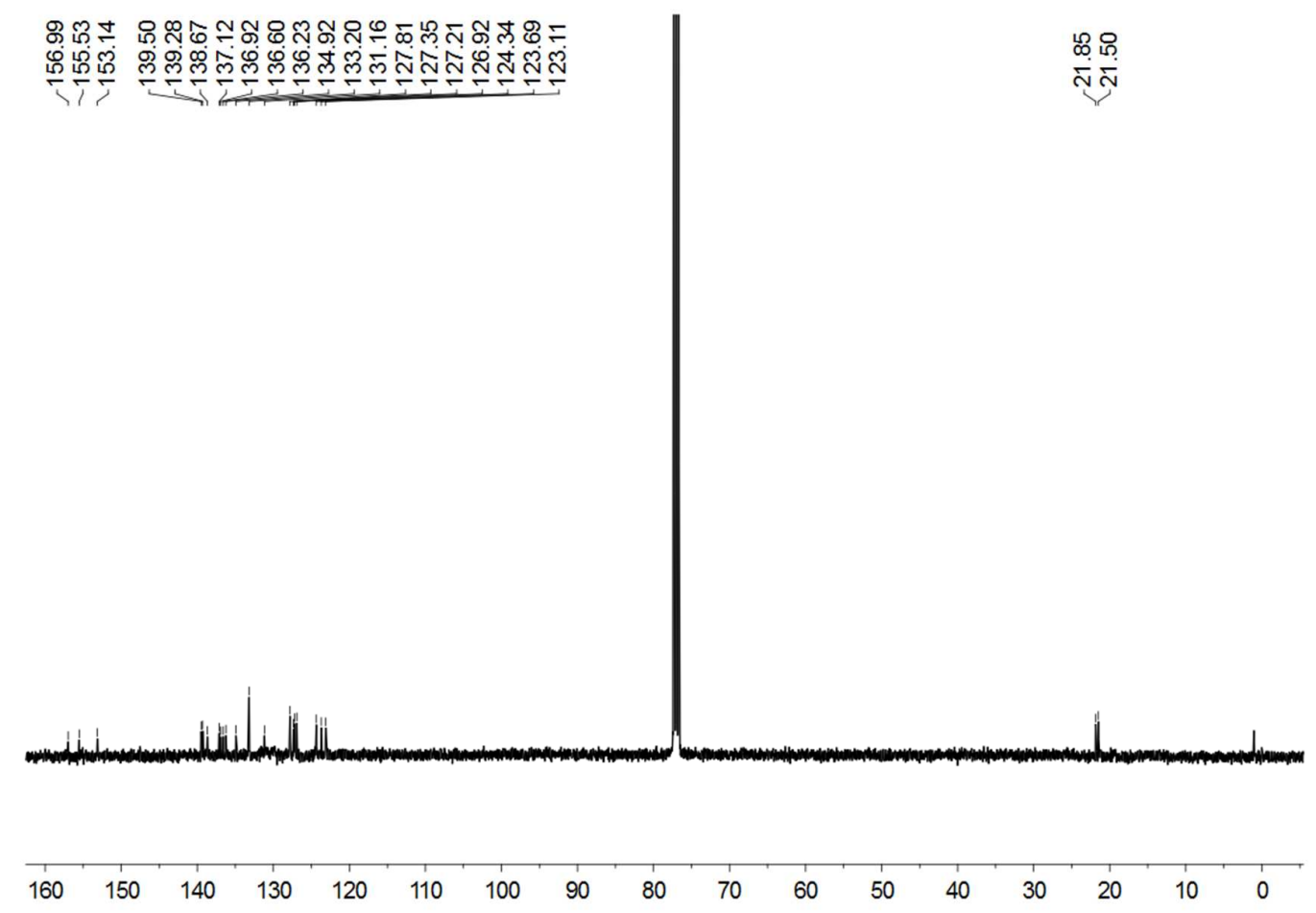

Figure S4. ${ }^{13} \mathrm{C}$ NMR spectra of $\mathbf{2 a}$ in $\mathrm{CDCl}_{3}$ at $298 \mathrm{~K}$. 


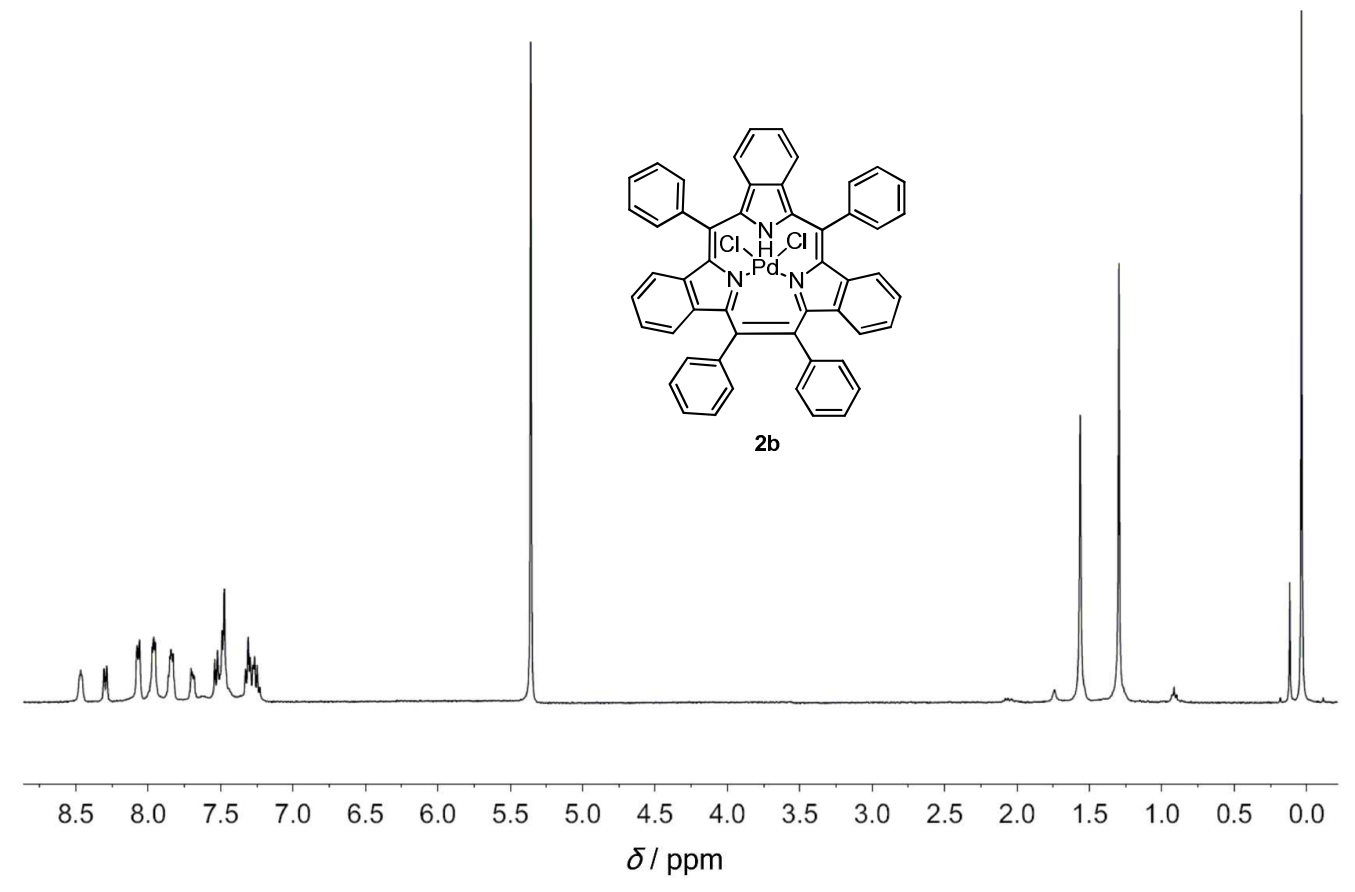

Figure S5. ${ }^{1} \mathrm{H}$ NMR spectra of $\mathbf{2 b}$ in $\mathrm{CD}_{2} \mathrm{Cl}_{2}$ at $298 \mathrm{~K}$
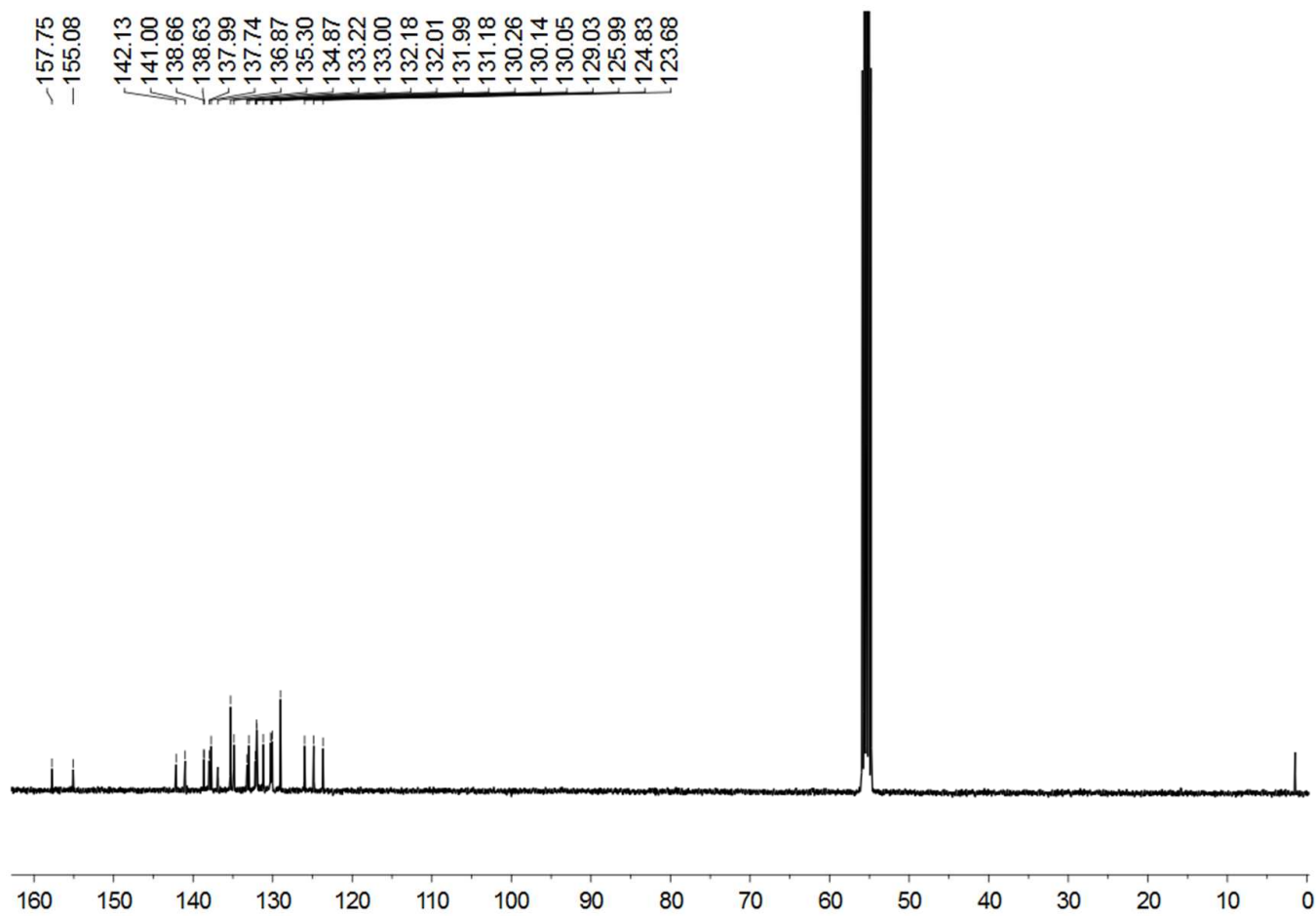

Figure S6. ${ }^{13} \mathrm{C}$ NMR spectra of $\mathbf{2 b}$ in $\mathrm{CD}_{2} \mathrm{Cl}_{2}$ at $298 \mathrm{~K}$. 
(a) $\mathrm{CH}_{3}-\mathrm{Pd}^{\text {II-TriP } 2 \mathrm{a}}$

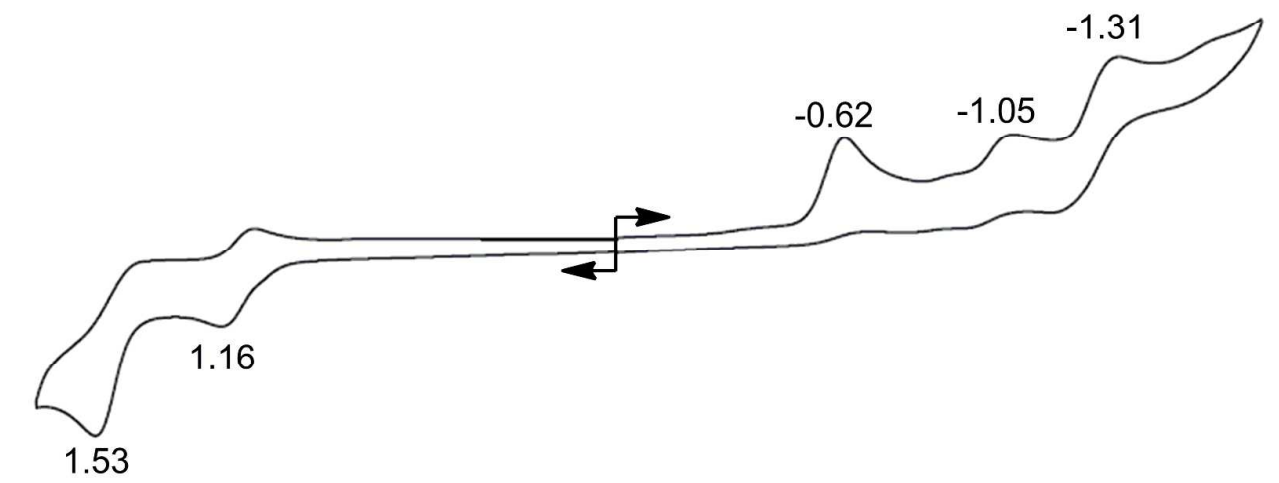

(b) H-Pd"l-TriP $2 \mathbf{b}$

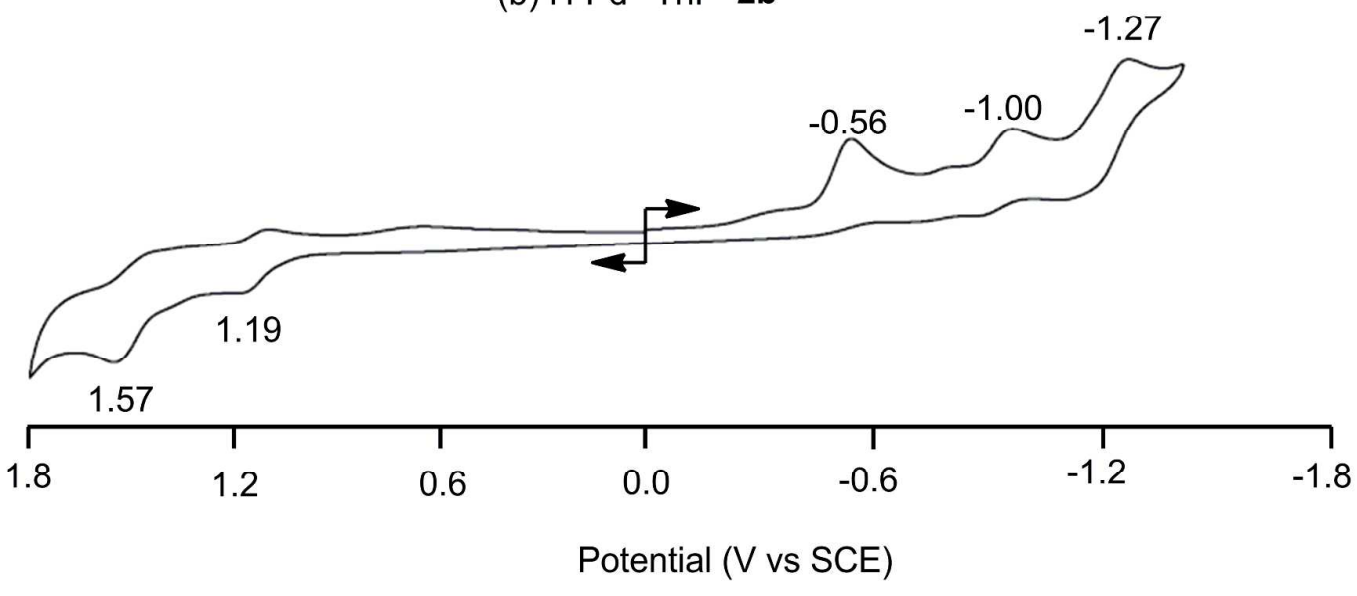

Figure S7. Cyclic voltammograms of (a) $\mathbf{2 a}$ and (b) $2 \mathbf{b}$ in $\mathrm{CH}_{2} \mathrm{Cl}_{2}$ containing $0.1 \mathrm{M}$ TBAP. 